OPEN ACCESS

UNIVERSITY OF THE

WEST of SCOTLAND

UWS Academic Portal

\title{
Creating positive experiences for people living with dementia in care homes
}

Callaghan, Margaret; Ritchie, Louise

Published in:

Nursing Older People

DOI:

10.7748/nop.2017.e871

Published: 31/01/2017

Document Version

Peer reviewed version

Link to publication on the UWS Academic Portal

Citation for published version (APA):

Callaghan, M., \& Ritchie, L. (2017). Creating positive experiences for people living with dementia in care homes. Nursing Older People, 29(1), 36-39. https://doi.org/10.7748/nop.2017.e871

\section{General rights}

Copyright and moral rights for the publications made accessible in the UWS Academic Portal are retained by the authors and/or other copyright owners and it is a condition of accessing publications that users recognise and abide by the legal requirements associated with these rights.

Take down policy

If you believe that this document breaches copyright please contact pure@uws.ac.uk providing details, and we will remove access to the work immediately and investigate your claim. 


\section{Creating a Positive Care Home Experience for People Living with Dementia: A narrative review of the literature}

\section{Abstract}

Background: Alzheimer's disease International (2015) acknowledges the increased incidence of dementia. It is estimated that two thirds of people with dementia live in care homes. As the incidence of dementia is expected to increase as the population ages, it is imperative that we understand the factors which create a positive care home environment to ensure a positive care experience for people living with dementia.

Aim: This article aims to provide a review of the literature relating to creating a positive care home environment in order to improve understanding of the factors which contribute to improve care experiences for residents living with dementia. Method: A narrative review was undertaken to examine factors that influence care home environments. Nine databases were searched using a range of search terms relating to dementia and care homes.

Findings: The literature identified that both organisation culture and workforce development were important factors in creating a positive care home experience. Conclusion: Although the evidence is limited, it is essential to acknowledge that if the workforce are to gain the necessary knowledge and skills, a person centred approach based on research based evidence is essential

\section{Keywords:}

Care homes; Dementia or Alzheimer's disease; Dementia Training; Workforce Development; Culture; Quality of Care; 


\section{Introduction}

Alzheimer's Disease International (2015) acknowledges the increased incidence of dementia, with two thirds of residents supported in care homes living with this condition. The changing demographics of older people living with dementia is expected to increase in the next ten to twenty years. Health and social care experience many challenges due to the changing demographics therefore, it is essential that the policy drivers view dementia as a national priority if positive care home experiences are to be created. International Council of Nurses (2012) argue that if the quality of care within care homes is to improve then the gap between good performing and poor performing services needs to reduce.

Dementia is a national concern for governments in the UK. It is currently estimated that 800,000 people in the UK have a diagnosis of dementia, and this is predicted to rise to one million by 2025 (Alzheimer's Society, 2014). Dementia Strategies have been developed by devolved governments across the UK, with a focus on improving the wellbeing and support for people with dementia (Department of Health, 2009; Scottish Government, 2013). With this in mind, it is imperative that we understand the factors that contribute to creating a supportive and positive care home experience for people living with dementia. 


\section{Aim of the review}

This article aims to provide a narrative review of the literature relating to creating a positive care home environment in order to improve understanding of the factors which contribute to improved care experiences for residents living with dementia.

\section{Search Strategy}

Nine Databases (CINAHL, Medline, Health Source, SAGE journals, Science

Direct, PsycINFO, Taylor and Francis Journals, Web of Science, ProQuest) were searched using Boolean AND/OR for the keywords; Care homes; Dementia or Alzheimer's Disease; Dementia Training; Workforce Development; Culture;

Quality of Care. Inclusion criteria for the review are listed below.

- Publication date between 2006-2016

- Primary research or systematic reviews

- Research relating to care homes only.

The literature search returned 23 papers which met the inclusion criteria following based on the information on the title and abstract. Each paper was read in detail and key findings were extracted and are presented below.

\section{Findings}

\section{The Influence of Organisational Cultures}

The literature review found that the organisational culture may influence care home experiences (Luff et al. 2011) and quality of care in care homes (Beek and Gerritsen, 2010). One aspect of organisational culture is person centred care. The importance of person centred care is not a new concept; there is a vast 
amount of literature available which discusses the view that this approach underpins the foundations of relationships, resulting in positive outcomes for individuals living in care homes (Kitwood, 1993; Kitwood, 1997; McKeown et al. 2010). Likewise Sheard (2013) proposes that where organisations do not embrace a culture of person centred approaches, the workforce may not gain the necessary knowledge and skills to support people living with dementia. Additionally, the organisational learning culture may be important. A study by Grealish et al. (2014) was completed to ascertain the organisational learning cultures within three care homes. The results show that there may be a relationship between care home cultures where the importance of continual learning is more effective when a change facilitator is accessible (Tung et al. 2008; Grealish et al. 2014). Change facilitators support the workforce to adapt to change where they aim to motivate, value and involve people which results in improved performance as well as better staff retention (Taplin and Rasic, 2012). As a result of the studies presented it is concluded that where a learning culture is prevalent, there is an increased likelihood that a positive care home experiences will be created (Luff et al, 2011).

The type of organisational culture is also important to consider. An ethnographic study was undertaken by Nakrem (2015), focusing on understanding organisations with cultural principles for quality of care and suggests that for care homes to flourish, a culture of honesty and learning requires to be present (Nakrem, 2015). Beek and Gerritsen (2009) carried out a qualitative cross sectional-design using systematic observations and questionnaires to examine 
the relationship between the organisational cultures of care homes and the quality of care for residents living with dementia. They found an association between the culture of the care homes and the quality of care, and the findings imply that a clan culture may achieve improved quality of care. Nakrem (2015) relates organisational cultures within care homes to the quality of care provided, likewise Killet et al. (2016) recognises that there may be a link between care home cultures and the quality of care, however there is limited research to support this argument. Killet at al. (2016) suggests that care homes require to improve their understanding of organisational cultures if the gap between good quality of care and poor quality of care is to reduce. Dewar (2007) suggests that clan cultures improve care home environments as they build on relationships which support person centred approaches. A clan culture is described as a collaborative culture which is compared to a family like culture; this tradition focuses on working together and providing support for the workforce (Tharp, 2009). Scot et al. (2003) offer a similar point of view; care homes that promote a clan culture provide a better standard of care, as opposed to a hierarchy or market culture which are generally influenced by either authoritarian structures or competitiveness and profit (Tharp, 2009) .

\section{Creating a Skilled Workforce for Care Homes}

The need for increased workforce training and education in order to improve the experiences for people living with dementia in care homes has been widely acknowledged within the literature (Alzheimer's Society, 2007; Hughes et al., 2008; Wild et al. 2010; Stone and Harahan, 2010). The Alzheimer's Society 
(2007) argue that the workforce have insufficient knowledge and understanding to appropriately support people living with dementia if a positive care home experiences is to be achieved. Similarly, Stone and Harahan, (2010) recommend that if the workforce is to develop further then the policy drivers require to place more focus on resources to support this population where consideration is given to a competency based framework.

Board et al. (2012) discuss how education can improve care for residents living with dementia where the introduction of an interaction educational programme is considered. The results of the evaluation suggest that the workforce generally have a good knowledge base on how to support residents who live with dementia. However, Nakrem (2015) argues that although dementia training is provided to develop the workforce, it is vital that the messages learned are reviewed through reflection at regular intervals, due to the complex health needs experienced by some residents living with dementia. Dewar (2007) presents similar findings where the importance of continual learning is recommended if a positive learning environment is to be created within care homes.

Another important factor raised is that training opportunities increase staff confidence, abilities and responsibilities which aim to improve the quality of care for residents living in care homes (Wild et al. 2010). Therefore It is essential that the workforce gain the necessary skills to create a positive environment for people living with dementia however, it is also important that carers (formal) gain 
confidence if a culture of learning is to be achieved (Scottish Government, 2011; Walker and Gillies, 2013).

Key findings recognised in the studies discuss how dementia training influences staff performance and self-efficacy.(Wild et al. 2010; Walker and Gillies, 2013) However, several studies convey concerns with regards to the quality of the dementia training materials (Gould and Reed, 2009; Broughton et al. 2011; Spector et al. 2013 and Fossey et al. 2013). Also, the quality of dementia training may be a contributing factor to the standard of care provided for example, whether training is easily accessed, up to date and evidence based. Spector et al. (2013) suggest that dementia training needs to be evidenced based if the standards of care are to be to a good standard. There is a wealth of evidence within the literature that suggests that dementia training materials are not being underpinned by evidence based research (Fleming and Fitzgerald, 2009; Spector et al. 2013; Fossey et al. 2014). Therefore, if a positive care home experience is to be created it is important that the workforce gain the necessary knowledge and skills based on learning frameworks that are evidence based (Dewar, 2007).

The effectiveness of dementia training may be measured by the level of knowledge and understanding gained from staff following training sessions (Gould and Reed, 2009). Hughes et al. (2008) discuss the positive impact that an increased knowledge of dementia has on the quality of the care provided for residents who live with dementia. Nolan et al. (2006) suggest that further research is required to ascertain how the workforce knowledge and skills 
influences quality of care for people living with dementia in care homes if good practice is to be recognised. However, Fleming and Fitzgerald (2009) recognise several issues that may be a challenge when the introduction of dementia training is implemented to support the workforce within care homes for example, the diverse cultural backgrounds of staff or the difficulties that may develop when attempting to release staff from their shift to attend training.

\section{Limitations of the review}

This paper was UK focused and might not be applicable to a wider international audience. In addition, it does not consider the presence of co-morbidities of residents living with dementia in care homes, which may further impact on the care home experience. This paper aimed to provide a narrative of the current situation as presented in the literature and as such has made no attempt to critically appraise the methodology of each study included. Future work in this area may include a systematic review which identifies the strength of the evidence for both workforce training and organisational cultures in creating a positive care home experience.

\section{Implications for practice}

There is a limited amount of research which focuses on the organisational cultures of care homes and how these relate to the experiences of people living with dementia in care homes. However, the emerging evidence suggests a clan culture may be linked to more positive care home experience. Research and policy clearly suggests that effective person centred care and outcomes create 
positive care home experiences. However research linking the effectiveness of person centred approaches with specific organisational cultures is limited. This paper recommends that further research linking care home culture with the quality of care experienced by people living with dementia is essential, if positive care home experiences are to be created. While the evidence-based practice to support positive care home environments is limited, it is important to recognise that there are models of good practice, for example My Home Life Programme (Dewar, 2016). International Council of Nurses (2012) suggests that collaborative approaches are essential if the experiences of people living with dementia in care homes are to improve.

The findings of the review indicate that there is a limited amount of research which focuses on the organisational cultures of care homes and how these relate to the experiences of people living with dementia in care homes. Therefore this paper recommends that further research linking care home cultures with the quality of care experienced by people living with dementia is essential, where the recommendations highlighted below are considered.

\section{Recommendations:}

- Care Inspectorate place more focus on person centred care as opposed to compliance models (Cook and Miller, 2012)

- Care home providers build on relationships with the Care Inspectorate to improve quality of care. 
- Researchers and practitioners work together to transfer evidence based practice within care homes (International Nurses Day, 2012)

- Effective methods are introduced to reduce the gap between theory and practice (Crooke and Olswang, 2015).

- The workforce gain sufficient knowledge and understanding of the factors that create a positive care home environment where effective evaluation is carried out (Draper et al. 2009)

\section{Conclusion}

This review examines the evidence of the factors which contribute to creating a positive care home experience for people living with dementia. The key findings in the literature are identified; the influence of organisational cultures on care home environments and the importance of creating a skilled workforce for care homes. The literature suggests that a clan culture is the preferred approach if a positive care home environment is to be achieved for people living with dementia; however the empirical evidence is limited for this population (Killett et al. 2016). Grealish et al. (2014) highlight that learning cultures within care homes are essential however, where a culture change is suggested it may be necessary to access a change facilitator if a positive environment is to be created (Grealish et al. 2014). Although, it is also important to recognise that the culture within care homes require to be embraced by management if the ethos is to create a positive environment (Sheard, 2013).

Dewar (2007) and Sheard (2013) recommend that if the workforce is to gain the necessary knowledge and skills a person centred approach based on research 
based evidence is essential. However, the literature suggests that the workforce within care homes do not have sufficient knowledge and skills to support this population. Although, it is important to recognise the care homes that create a positive care home experience and share good practice to improve the image of care homes (Owen et al. 2012; Burtney et al. 2014). If quality of care in this setting is to continue to improve it is essential that dementia remains a Government priority where the culture within care homes embraces an ethos that enables the workforce to develop. Also, it is essential that when the Care Inspectorate carries out their inspections that they work in partnership with those involved if a positive care home experience is to be created.

\section{References}

Alzheimer's Society (2007) Home from Home: A Report Highlighting Opportunities for Improving Standards of Dementia Care in Care Homes Alzheimer's Society: London

Alzheimer's Society (2014) Dementia 2014: Opportunity for Change [Online] Available: https://www.alzheimers.org.uk/site/scripts/download info.php?filelD=2317 [Last accessed: 22 October 2016] 
Alzheimer's Disease International (2015) World Alzheimer's Report 2015: The Global Impact of Dementia - An Analysis of Prevalence, Incidence, Cost and Trends_Online] Available:

https://www.alz.co.uk/research/WorldAlzheimerReport2015.pdf

[Last accessed: 19 September 2015]

Beek APA van and Gerritsen DL (2010) The relationship between organizational culture of nursing staff and quality of care for residents with dementia: Questionnaire surveys and systematic observations in nursing homes International Journal of Nursing Studies. 47, 1274-1282

Board M, Heaslip V, Fuggle K, et al (2012) How education can improve care for residents with dementia Nursing Older People. 24, 5, 29-31

Broughton M, Smith ER, Baker R, et al (2011) Evaluation of a Caregiver Education Program to Support Memory and Communication in Dementia: A controlled Pretest-Posttest Study with Nursing Home Staff International Journal of Nursing Studies. 48, 1436-1444

Burtney L, Figgett D, Fullerton D,et al (2014) Learning for Care Homes from Alternative Residential Care Settings Joseph Rowntree Foundation: York 
Cook and Miller (2012) Talking Points: Personal Outcomes Approach-Practical Guide Joint Improvement Team: Edinburgh

Crooke, P.J and Olswang, L.B. (2015) Practice-Based Research: Another Pathway for Closing the Research-Practice Gap Journal of Speech and Language and Hearing Research 58, Supplement, S1871-S1882 Department of Health (2009) Living well with Dementia: A National Dementia Strategy Department Health: London

Dewar B (2007) Promoting Positive Culture in Care Homes In: Help the Aged. My Home Life: Quality of Life in Care Homes Help the Aged: London. 148--156

Dewar B (2016) My Home Life Leadership Programme [Online] Available: http://myhomelife.org.uk/resources-and-information/care-homes/my-home-life-inyour-care-home/ [Last accessed: 2 April 2016]

Draper B, Low CR, Withall A et al (2009) Translating Dementia Research into Practice International Psychogeriatrics 21, Supplement 1, S72-S80

Eggenberger E, Heimerl , Bennet MI (2012) Communication Skills Training in Dementia Care: a Systematic Review of Effectiveness, Training Content, and Didactic Methods in Different Care Settings International Psychogeriatrics.1-14 
Fleming R and FitzGerald D (2009) Large-scale training in the essentials of dementia care in Australia: Dementia Care Skills for Aged Care Workers project International Psychogeriatrics. 21, Supplement 1, S53-S57

Fossey J, Masson S, Stafford J, et al (2014) The Disconnect Between Evidence and Practice: a Systematic Review of Person-Centred Interventions and Training Manuals for Care Home Staff Working with et al People with Dementia International Journal of Geriatric Psychiatry. 29, 797-807

Grealish L, Henderson A, Quero F, (2014) The Significance of 'Facilitator as a Change Agent' -Organisational Learning Culture in Aged Care Home Settings Journal of Clinical Nursing. 24, 961-969

Gould E and Reed P (2009) Alzheimer's Association Quality Care Campaign and Professional Training Initiatives: Improving Hands-on Care for People with Dementia in the U.S.A. International Psychogeriatrics. 21, Supplement 1, S25S33

International Council of Nurses (2012) Closing the Gap: From Evidence to Action [Online] Available:

http://nursingworld.org/MainMenuCategories/ThePracticeofProfessionalNursing/l mproving-Your-Practice/Research-Toolkit/ICN-Evidence-Based-PracticeResource/Closing-the-Gap-from-Evidence-to-Action.pdf [Last accessed: 24 April 2016] 
Killet A, Burns D, Kelly F, et al (2016) Digging Deep: How Organisational

Culture Affects Care Home Resident's Experience. Ageing and Society. 36, 1, $160-188$

Kitwood T (1993) Towards a theory of dementia care: the interpersonal process. Ageing and Society. 13, 51-67.

Kitwood T (1997) Dementia Reconsidered: The Person Comes First. Open University Press, Buckingham

Hughes J, Bagley H, Reilly S, et al (2008) Care staff working with people with dementia: Training, Knowledge and Confidence Dementia [Online] Available: http://dem.sagepub.com/content/7/2/227.abstract [Last accessed: 06 February 2016]

Luff R, Ferreira Z, Meyer J (2011) Care Homes: Improving the Evidence Base for Adult Social Care Practice National Institute for Health Research: London 
McKeown J, Clarke A, Ingleton C,et al (2010) The use of Life Story Work with People with Dementia to Enhance Person Centred Care International Journal of Older People Nursing. Blackwell Publishing

Nakrem S (2015) Understanding Organisational and Cultural Premises for Quality of Care in Nursing Homes: An Ethnographic Study Research Article. 508, $1-15$

Nolan M, Davies S, Brown J (2006) Transitions in Care Homes: Towards Relationship-Centred Care using the SENSES Framework Quality in Ageing Policy, Practice and Research. 7, 3, 5-14

Owen T, Meyer J, Cornwell M ,et al (2012) My Home Life: Promoting Quality of Life in Care Homes Joseph Rowntree: York

Scott T, Mannion R, Marshall M et al . (2003) Does organisational culture influence health care performance? A review of the evidence. Journal of Health Services Research \& Policy. 82, 105-117. 
Scottish Government (2011) Promoting Excellence: A Framework for all Health and Social Services Staff Working with People with Dementia, their Families and Carers_Scottish Government: Edinburgh [Online] Available:

http://www.scotland.gov.uk/Resource/Doc/350174/0117211.pdf [Last accessed: 20 October 2012]

Sheard D (2013) Steering:_Culture Change Matters in Dementia Care Homes Dementia Care Matters: Brighton

Spector A, Orrell M,Joyder J (2013) A systematic Review of Staff Training Interventions to Reduce the Behavioural and Psychological Symptoms of Dementia Ageing Research Reviews. 12, 354-364

Stone R and Harahan MF (2010) Improving the Long-Term Care Workforce Serving Older Adults Health Affairs. 29, 1, 109-115

Taplin DH and Rasic M (2012) Facilitators Source Book: Leading Theory of Change Development Sessions [Online] Available:

http://www.theoryofchange.org/wpcontent/uploads/toco library/pdf/ToCFacilitatorSourcebook.pdf [Last accessed: 22 October 2016]

Tharp BM. (2009) Four Organisational Culture Types Haworth [Online] Available: http://faculty.mu.edu.sa/public/uploads/1360757023.3588organizational\%20cult9 8.pdf [Last accessed: 23 April 2016] 
Tung SMW, Boschma G, Phinney A (2008) Residential Elder Care in

British Columbia: Policy Development and Culture Change (1950 - 2005)

Perspectives. 34, 4, 5-16

Walker G and Gillies L (2013) "Sliding Doors": Innovative Approaches to Supporting Culture Change Journal of Integrated Care, 22, 4,154-164

Wild D, Szczepura A, Nelson S. (2010) Residential Care Home Workforce Development: A Rhetoric and reality of Meeting Older Residents' Future Needs Josephine Rowntree Foundation: York 